\title{
Comparison of Attention Levels in Primary School Students in Terms of Gender and Physical Activity
}

\author{
Meliha Uzun Dönmez ${ }^{\circledR}$ \\ Osman İmamoğlu² (D)
}

'Sirnak University, School of Pyhsical Education and Sports, Sirnak, Turkey. Email:melihauzunn16@gmail.com

${ }^{2}$ Yasar Dogu Faculty of Sports Sciences, Ondokuz Mayzs University, Samsun, Turkey.

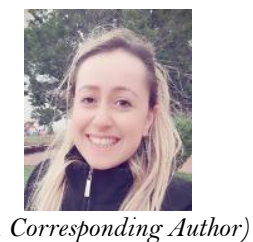

\section{Abstract}

The aim of this study was to compare attention levels of primary school students in terms of gender, school and physical activity. The study included a total of 301 primary school students, of whom 144 were female and 157 were male. Data were collected with Physical Activity Questionnaire and D2 Test of Attention. Pair-wise categorical comparisons were made with $t$ test. There was a significant difference in scores for D2 Test of Attention and its subscales psychomotor speed and selective attention between genders $(\mathrm{p}<0.05)$, while the difference in special learning difficulty, concentration performance and physical activity was insignificant $(\mathrm{p}>0.05)$. Attention levels did not significantly differ between the students in state primary schools and those in private primary schools, either $(p>0.05)$. The students were similar in physical activity and attention performance scores. To conclude, gender was found to play a significant role in psychomotor speed, selective attention level and total performance in $\mathrm{D} 2$ Test of Attention. All the students had moderate physical activity, which did not significantly differ between the students. In addition, attention levels were not different between state schools and private schools. However, the students with high physical activity were found to have higher attention performance. Therefore, primary school students should be enabled to have more physical activity to improve their attention.

Keywords: Physical activity, D2 test of attention, Student, Psychomotor speed, Concentration, Selective attention level.

Citation | Meliha Uzun Dönmez; Osman İmamoğlu (2020). Comparison of Attention Levels in Primary School Students in Terms of Gender and Physical Activity. Asian Journal of Education and Training, 6(2): 256-260

History:

Received: 21 January 2020

Revised: 3 March 2020

Accepted: 6 April 2020

Published: 23 April 2020

Licensed: This work is licensed under a Creative Commons

Attribution 3.0 License (co)

Publisher: Asian Online Journal Publishing Group
Acknowledgement: Both authors contributed to the conception and design of the study.

Funding: This study received no specific financial support

Competing Interests: The authors declare that they have no conflict of interests.

Transparency: The authors confirm that the manuscript is an honest, accurate, and transparent account of the study was reported; that no vital features of the study have been omitted; and that any discrepancies from the study as planned have been explained.

Ethical: This study follows all ethical practices during writing.

\section{Contents}

1. Introduction

2. Material and Method

3. Results

References 


\section{Contribution of this paper to the literature}

This study contributes to existing literature by comparing attention levels of primary school students in terms of gender, school and physical activity.

\section{Introduction}

Attention is defined as an activity of the nervous system which enables showing interest in only the stimuli related to instant needs and goals (Banich, 1997; Kolb \& Winshaw, 1996; Parasuraman, 2000). Focusing, concentration and consciousness are the basis of attention. It is considered as an action of selecting and identifying any one of the sensorial stimuli based on some goals. It is the action of consciously focusing on stimuli. Consciousness reveals decreased capacity in focusing, and other stimuli are eliminated before they reach the conscious because information to be transferred from sensorial memory to short-term memory for advanced processing is recognized through attention (Gözalan, 2013; Oztürk \& Kısaç, 2010). Attention refers to some part of a response shaped by the physical and social environments and initiation of learning (Ruff \& Rothbart, 2001). Sports has a positive effect on physical and mental development of students. A good body posture or posture development is required in the performance development of students. It is a known fact that sport plays a role in the development of people physically and mentally (Atan, Tural, Imamoğlu, Ciçek, \& Tural, 2012; Yamak, Imamoğlu, Islamoğlu, \& M., 2018).

Behavioral development of attention and neural development of attention accompany each other. Attention depends on almost all regions of the brain. First, the brainstem controls the general level of a stimulation in the cortex. Visual and tactile or sensorial perceptions should be developed in early childhood. Children perceive information filtered from stimuli through senses. The information filtered through sensorial organs stimulate nerves. These stimuli are recorded by senses for a second. Certain points access the short-term memory and others disappear (Arslan, 2008). Selective attention is direction of perception to one or two stimuli at a time and exclusion of other stimuli (Asan, 2011; Kılıç, 2002). In the absence of focusing on a certain target, attention is meaningless. Processes in selectiveness are mostly necessary for the management ability of stimuli and information (Ruff \& Rothbart, 2001). During selective attention, the body selects the most important features for itself (Gözalan, 2013; Tunç, 2013). D2 Test of Attention is considered as an indicator of selective attention and ability to think.

Physical activity causes contractions of the skeletal muscles, which requires spending energy more than the basal metabolism (Caspersen, Powell, \& Christenson, 1985). Physical activity during childhood and adolescence not only allows having the highest performance in sports but also contributes to improvement and protection of health (Bailey \& Martin, 1994). To understand the psychological and physical processes that may contribute to the quality of performance, investigating the psychological and physical structures associated with optimal performance has been the focus of researchers (Akyol \& Imamoğlu, 2019). In the last 30 years, a lot of research has been done to control and manage the emotions of people (Goodman, Kashdan, \& İmamoğlu, 2020). Attention is affected by emotional state.

Most of the primary schools in Turkey are state schools. In addition, there are private primary schools. The latter group of schools attempt to make money and want to have a high rate of success by recruiting successful students, which may not be always achieved. There has been an interest in whether students in state primary schools and those in private primary schools differ in terms of attention levels. Therefore, the present study was directed towards comparing attention levels of primary school students in terms gender, type of school and physical activity.

\section{Material and Method \\ 2.1. Study Group}

The study included state and private primary schools. Data were collected by using D 2 Test of Attention and Physical Activity Questionnaire. A total of 301 students fulfilling the data collection tools completely, of whom 144 were female and 157 were male, were included into the study sample.

\subsection{Data Collection Tools}

Physical Activity Questionnaire: Physical Activity Questionnaire for primary school students was adapted to Turkish by Sert and Temel (2014). It is used to measure physical activity of children aged 4-14 years in the previous seven days. It can be administered in class and offers information about general physical activities. The scores five and one for the questionnaire indicate the highest physical activity and the lowest or poorest physical activity respectively. The mean total score for the questionnaire is used to evaluate physical activity. Based on their scores, children are classified into inactive, moderately active and active.

D2 Test of Attention: The test was adapted to Turkish culture by Toker (1988). Its validity and reliability were tested on Turkish sportsmen by Cağlar and Koruç (2006) and on children aged 9-13 years by Yaycr (2013). It was found to be acceptable to use in children aged 11-14 years. D2 Test of Attention is used to measure selective attention and focusing attention. In the test, there is a line for trial and a section where personal features and performance results of test takers can be recorded. On the test page, there are 14 lines, each of which contains 47 letters, composed of 16 different small $\mathrm{p}$ and d letters depending on the place and number of marks. There is one, two, three or four marks above or below these letters. Test takers have to find all d letters with two marks in all lines and ignore the other letters. They are given 20 seconds for each line. Scores for psychomotor speed, selective attention level, special learning difficulty, test performance and concentration performance are taken into account to evaluate the results of the test. The test performance scores of $50 \%-60 \%, 60 \%-70 \%, 70 \%-85 \%$ and $85 \%$ and higher are considered as poor, average (somewhat better than poor), normal and good respectively (Cağlar \& Koruç, 2006). Psychomotor speed refers to the number of marked figures. In other words, it is the numerical value of performance related to all relevant or irrelevant figures marked. Selective attention level refers to the number of letters or figures unmarked but supposed to be marked. In other words, it is the number of correct letters unmarked. A high number of these letters indicates low selective attention and an insufficient quality of 
performance. Special learning difficulty refers to the number of wrong letters marked. A high number of wrong letters marked shows special learning difficulty, difficulty in adapting to the instruction, carelessness and deficiencies in discriminating what is seen. Percentage of mistakes is used to evaluate the qualitative aspect of performance and is the rate of mistakes in all markings. As the rate of mistakes individuals make decreases, their ability to make accurate decisions, the quality of their decisions and attention levels increase. The total itemsmistakes (TI-M) refers to subtraction of the number of mistakes from the total number of letters marked. It is considered as the total performance score or test performance. TI-M has a normal distribution and is even very reliable. Therefore, it means the value of the relation between accuracy of performance and speed of performance. However, TI-M underlines the quantitative aspect of performance more than its qualitative aspect. In unusual conditions, extremely high quantitative and qualitative scores (total score and percentage of mistakes) may cause overestimation of total performance. To avoid such overestimations, the score for mistakes or concentration performance is taken into account. Concentration performance is obtained by subtracting the number of wrong figures marked from the number of correct figures marked. In contrast to TI-M, concentration performance is not affected by marking all letters without distinguishing them or randomly skipping test sections. It is considered as the best index for accuracy of performance and coordination of speed (Cağlar \& Koruç, 2006).

\subsection{Data Analysis}

Data were analyzed with SPSS 22.00. Kolmogorov-Smirnov and Shapiro-Wilk tests were used to determine whether data about variables were normally distributed. Pair-wise categorical comparisons were made with $t$ test.

\section{Results}

Table-1. Comparison of attention and physical activity between genders.

\begin{tabular}{l|c|c|c|c|c|c}
\hline \multirow{2}{*}{ Variables } & \multicolumn{2}{|c|}{ Female $(\mathbf{n = 1 4 4})$} & \multicolumn{2}{|c|}{ Male $(\mathbf{n = 1 5 7})$} & \multirow{2}{*}{$\mathbf{p}$} \\
\cline { 2 - 6 } & Mean & SD & Mean & SD & & \\
\hline Psychomotor speed & 400.48 & 91.82 & 374.1 & 97.54 & 2.47 & $0.036^{*}$ \\
\hline Selective attention level & 55.87 & 51.20 & 43.59 & 45.19 & 2.44 & $0.045^{*}$ \\
\hline Special learning difficulty & 21.14 & 31.03 & 27.28 & 24.53 & -1.77 & 0.190 \\
\hline Test performance & 361.97 & 82.51 & 338.66 & 79.56 & 2.67 & $0.038^{*}$ \\
\hline Concentration performance & 90.83 & 45.23 & 85.61 & 46.32 & 1.44 & 0.280 \\
\hline Physical activity levels & 3.01 & 1.01 & 3.27 & 1.07 & 1.07 & 0.196 \\
\hline Note ${ }^{*}$ p $<0.05$ & & & &
\end{tabular}

$$
\text { Note: }{ }^{*} \mathrm{p}<0.05 \text {. }
$$

The comparison of attention performance showed a significant difference in psychomotor speed, selective attention levels and total performance in $\mathrm{D} 2$ Test of Attention between genders $(\mathrm{p}<0.05)$, Table 1 .

\begin{tabular}{|c|c|c|c|c|c|c|}
\hline \multirow[t]{2}{*}{ Gender } & \multirow[t]{2}{*}{ Variables } & \multicolumn{2}{|c|}{ State Primary Schools } & \multicolumn{2}{|c|}{ Private Primary Schools } & \multirow[t]{2}{*}{ t-test } \\
\hline & & Mean & SD & Mean & SD & \\
\hline \multirow[t]{5}{*}{ Female } & Psychomotor speed & 397.57 & 90.92 & 403.38 & 99.47 & -0.33 \\
\hline & Selective attention level & 52.78 & 50.26 & 58.95 & 50.45 & -0.85 \\
\hline & Special learning difficulty & 21.62 & 30.12 & 20.66 & 20.12 & 0.34 \\
\hline & Test performance & 360.37 & 85.13 & 363.57 & 86.17 & -0.31 \\
\hline & Concentration performance & 90.52 & 44.50 & 91.14 & 43.13 & -0.09 \\
\hline \multirow[t]{5}{*}{ Male } & Psychomotor speed & 363.87 & 98.24 & 384.33 & 93.90 & 1.42 \\
\hline & Psychomotor speed & 42.43 & 42.17 & 44.75 & 45.22 & 0.33 \\
\hline & Special learning difficulty & 27.47 & 25.59 & 27.09 & 32.90 & -0.08 \\
\hline & Test performance & 328.92 & 88.10 & 348.41 & 87.90 & 1.36 \\
\hline & Concentration performance & 82.92 & 48.38 & 88.30 & 45.32 & 0.66 \\
\hline
\end{tabular}

Note: $\mathrm{p}>0.05$.

No significant difference in attention levels in both female and male students between the state primary schools and private primary schools $(\mathrm{p}>0.05)$, Table 2 .

Table-3. Distribution of percentages of physical activity and TI-M according to genders.

\begin{tabular}{|c|c|c|c|c|c|c|c|c|c|}
\hline \multirow[t]{3}{*}{ Genders } & \multirow[t]{3}{*}{ TI-M Level (Performance Score) } & \multicolumn{8}{|c|}{ Physical Activity Level } \\
\hline & & \multicolumn{2}{|c|}{ Low } & \multicolumn{2}{|c|}{ Moderate } & \multicolumn{2}{|c|}{ High } & \multicolumn{2}{|c|}{ Total } \\
\hline & & $\mathbf{n}$ & $\%$ & $\mathbf{N}$ & $\%$ & $\mathbf{N}$ & $\%$ & $\mathbf{N}$ & $\%$ \\
\hline \multirow{5}{*}{$\begin{array}{l}\text { Female } \\
(n=144)\end{array}$} & Poor $(50-60 \%)$ & 25 & 56.82 & 25 & 28.09 & 1 & 9.10 & 51 & 35.42 \\
\hline & Average $(61-70 \%)$ & 16 & 36.36 & 23 & 25.84 & 2 & 18.18 & 41 & 28.47 \\
\hline & Normal (71-85\%) & 2 & 4.55 & 21 & 23.60 & 3 & 27.27 & 26 & 18.06 \\
\hline & Good ( $86 \%$ and higher) & 1 & 2.27 & 20 & 22.47 & 5 & 45.45 & 26 & 18.06 \\
\hline & Total & 44 & 100 & 89 & 100 & 11 & 100 & 144 & 100.00 \\
\hline \multirow{5}{*}{$\begin{array}{l}\text { Male } \\
(\mathrm{n}=157)\end{array}$} & Poor $(50-60 \%)$ & 33 & 47.14 & 20 & 27.78 & 1 & 6.67 & 54 & 34.39 \\
\hline & Average (61-70\%) & 23 & 32.86 & 19 & 26.39 & 3 & 20.00 & 45 & 28.66 \\
\hline & Normal (71-85\%) & 12 & 17.14 & 18 & 25.00 & 4 & 26.67 & 34 & 21.66 \\
\hline & Good ( $86 \%$ and higher) & 2 & 2.86 & 15 & 20.83 & 7 & 46.67 & 24 & 15.29 \\
\hline & Total & 70 & 100 & 72 & 100 & 15 & 100 & 157 & 100 \\
\hline
\end{tabular}

Note: f: Frequency \%: Percentage.

The students were similar in terms of physical activity levels and attention performance scores. A high rate of both girls and boys with poor attention performance scores had low physical activity levels Table 3. 


\section{Discussion and Conclusion}

Several studies on attention have shown that girls are better at focusing their attention than boys (Bektaş, 2019; Borchert, 1998; Toker, 1988). However, Cağlar and Koruç (2006) did not find a significant difference in scores for D2 Test of Attention between females and males. In the present study, the comparison of attention performance showed a significant difference in psychomotor speed, selective attention levels and total performance in D2 Test of Attention between genders $(\mathrm{p}<0,05)$, but revealed no significant difference in special learning difficulty and concentration scores and physical activity levels ( $>>0,05)$, Table 1 . In a study by Orhan (2018) both boys and girls were found to have moderate physical activity. In addition, no significant difference was detected between physical activity levels and attention levels of the children. Renk (2019) also found similar physical activity levels between girls and boys in the experimental and control groups. The current study also revealed that the students did not differ in terms of physical activity and had moderate levels of physical activity. Keskin, Çubuk, Alpkaya, and Öztürk (2017) reported that male students got higher mean scores of physical activity. Several other studies also revealed higher physical activity levels in favor of males, though the difference was not significant (Aksoydan \& Çakır, 2011; Kaymaz \& Irez, 2016; Kudaş, Ülkar, Erdoğan, \& Cirçı, 2005; Sanlıer, 2005; Tunç. \& Işler, 2007). Consistent with the literature, the present study showed that physical activity did not significantly differ between genders.

In Toker (1988) state secondary school students were found to have lower attention levels than private secondary school students. However, this study revealed no significant difference in attention levels in both female and male students between the state primary schools and private primary schools ( $p>0.05)$, Table 2 .

Moran (2004) offered a ten-week psychological skills training to athletes and observed a significant increase in their selective attention and concentration scores. Urfa and Aşçı also reported that selective attention and concentration levels of athletes rose Urfa and Aşçı (2018). Göktepe, Akalın, and ve Göktepe (2016) in their comparative study found that skiing children had better attention than children not skiing Göktepe et al. (2016). In addition, Tunç (2013) reported a significant rise in attention in children aged 14-15 years after playing golf for eight weeks. Gelişli and Yazıcı found that an education game involving physical activity had a positive effect on attention in children aged 5-6 years (Gelli \& Yazici, 2016). Furthermore, Ibiş and Aktuğ (2018) compared attention between children doing sports and those not doing sports and reported high attention levels in the children doing sports. In Orhan (2018) most of both male and female children were shown to have high attention levels. In Renk (2019) the rate of female students having good physical activity in the pretest was $42,34 \%$, which increased to $59,46 \%$ in the posttest, and the rate of male students having good physical activity in the pretest was $44,04 \%$, which increased to $54,13 \%$ in the post test. In studies by Orhan (2018) and Renk (2019) the students were found to have moderate levels of physical activity and there was no significant relation between physical activity levels and attention levels. In the present study, the students were similar in terms of physical activity levels and attention performance scores. A high rate of both girls and boys with poor attention performance scores had low physical activity levels. The highest rate of both girls and boys with the worst or average attention performance scores had moderate physical activity. The highest rate of the students with high attention performance scores had high physical activity Table 3. It can be suggested that students with high physical activity have high attention performance scores. Therefore, physical activity of students should be increased to improve their attention performance.

In the current study, psychomotor speed, selective attention and total D2 test performance significantly differed between genders. The students had moderate physical activity without a significant difference. In addition, attention levels were not significantly different between the students from state primary schools and those from private primary schools. Furthermore, the students with high physical activity had attention performance scores. It can be recommended that primary school students should be enabled to have higher physical activity to enhance their attention performance.

\section{References}

Aksoydan, E., \& Çakır, N. (2011). Nutritional habits, physical activity levels and body mass indexes of adolescents. Gülhane Medical Journal, $53(4), 268-269$

Akyol, P., \& Imamoğlu, O. (2019). The relationship between motivation and flow states in sports faculty students. Asian Journal of Education and Training, 5(3), 440-446.

Arslan, M. (2008). Today is montessori pedagogy. Journal of National Education, 177, 65-79.

Asan, R. (2011). The effect of eight week table tennis exercise on attention in children between the ages of 9-13. Unpublished Master's Thesis, Selcuk University Institute of Health Sciences, Konya.

Atan, T., Tural, E., Imamoğlu, O., Ciçek, G., \& Tural, Ş. (2012). Physical activity levels of teachers and health professionals in Turkey Health MED, 6(6), 1935-1942.

Bailey, D. A., \& Martin, A. D. (1994). Physical activity and skeletal health in adolescents. Pediatric Exercise Science, 6(4), 330-347.Available at: https://doi.org/10.1123/pes.6.4.330.

Banich, M. T. (1997). Attention. In: Neuropsychology, The neural bases of mental function (pp. 234-273). Boston: Houghton Mifflin Company.

Bektaş, F. (2019). Evaluation of D2 attention levels of orienteering national team athletes who are in education age. Journal of Education and Training Studies, 7(6), 49-55.Available at: https://doi.org/10.11114/jets.v7i6.4204.

Borchert, J. (1998). Effective training programs to increase school awareness. An overview for teaching staff in special schools. Special Educational Congress in Hanover. Retrieved from: www.Vdsbundesverband.de/material/kongress98/borchert. htm.

Cağlar, E., \& Koruç, Z. (2006). Reliability and validity of D2 attention test in athletes. Journal of Sports Sciences, 17(2), 58-80.

Caspersen, C. J., Powell, K. E., \& Christenson, G. M. (1985). Physical activity, exercise, and physical fitness: definitions and distinctions for health-related research. Public Health Rep, 100(2), 126-131.

Gelli, Y., \& Yazici, E. (2016). The effect of "I bought myself" game on the development of attention skills of children. TURAN-CSR, 8(31), 29-38.

Göktepe, M., Akalın, T., \& ve Göktepe, M. M. (2016). An analysis of attention levels of children involved in the sport of skiing. International Journal of Science Culture and Sport, 4(3), 722-731.

Goodman, F. R., Kashdan, T. B., \& İmamoğlu, A. (2020). Valuing emotional control in social anxiety disorder: A multimethod study of emotion beliefs and emotion regulation. Emotion. Advance online publication. Retrieved from: http://dx.doi.org/10.1037/emo0000750. 
Gözalan, E. (2013). Investigation of the effect of game based attention training program on attention and language skills of 5-6 years old children. Unpublished Master Thesis. Selcuk University, Institute of Social Sciences, Konya.

Ibiş, S., \& Aktuğ, Z. B. (2018). Effects of sports on the attention level and academic success in children. Educational Research and Revierws, 13(3), 106-110.

Kaymaz, E., \& Irez, G. (2016). Comparison of pbesity, physical activity level and nutritional habits of secondary school students studying in public and private schools. Muğla Sıtkı Koçman University Institute of Health Sciences (Master Thesis).

Keskin, K., Çubuk, A., Alpkaya, U., \& Öztürk, Y. (2017). Investigation of the relationship between physical activity levels of 12-14 years old children and their nutritional behaviors. Journal of Sports Sciences of Istanbul University, 7(3), 34-43.

Kılıç, B. G. (2002). Theoretical models related to executive functions and attention processes and neuroanatomy. Journal of Clinical Psychiatry, $5(2), 105-110$.

Kolb, B., \& Winshaw, I. (1996). Attention, imagery, and consciousness. In: Fundamentals of human neuropsychology (pp. 465-489). New York: W.H. Freeman and Company.

Kudaş, S., Ülkar, B., Erdoğan, A., \& Cirçı, E. (2005). Ankara province physical activity and some nutritional habits of 11-12 age group children. Journal of Sport Sciences, 16(1), 19- 29.

Moran, A. (2004). Attention and concentration training in sport. (C Spielberger, Ed.) Encyclopedia of Applied Psychology (Vol. 1, pp. 209214): Academic Press.

Orhan, E. (2018). Investigation of the relationship between physical activity level, digital game addiction and attention levels of children between the ages of 10-14. Niğde Ömer Halisdemir University Institute of Social Sciences, Department of Physical Education and Sports Master Thesis, Niğde.

Oztürk, B., \& Kısaç, I. (2010). Information processing model. Educational psychology development-learning-Teaching 6th Edition (Edt. Yeşilyaprak, B.). Ankara: Pegem Academy.

Parasuraman, R. (2000). Issues and prospects. In: Parasuraman r ed. the attentive Brain (pp. 3-15). Cambridge: MA:MIT Press.

Renk, M. (2019). The effect of game activities on attention development in children of 10-13 age group. Niğde Ömer Halisdemir University Institute of Social Sciences Physical Education and Sports Master's Thesis.

Ruff, H. A., \& Rothbart, M. K. (2001). Attention in early development: Themes and variations (First Issued as an Oxford University Press Paperback): Oxford University Press, Network.

Sanlier, N. (2005). Biochemical findings, anthropometric measurements, body composition, nutrition and physical activity Status in Young People. Gazi Education Faculty Journal, 25(3), 47-73.

Sert, Z. E., \& Temel, A. B. (2014). Adaptation of the physical activity questionnaire for primary school students to the Turkish community: validity and reliability study. Dokuz Eylul University Faculty of Nursing Electronics Journal, 7(2), 109-1 14.

Toker, M. Z. (1988). Standardization of the visual attention test d2 on a Turkish sample. Unpublished Master's Thesis, Boğaziçi University Institute of Social Sciences.

Tunç, A. (2013). Investigation of attention levels of children playing golf. Unpublished Master Thesis, Selcuk University Institute of Health Sciences, Konya.

Tunç., i., \& Işler, A. (2007). Investigation of physical activity level of high school and university students by age and gender. Journal of Gazi Physical Education and Sports Sciences, 12(2), 11-18.

Urfa, O., \& Aşçı, F. H. (2018). Effect of ten weeks psychological skill training on anxiety, motivation, self-Esteem, attention and shot performance of Youth soccer players. Hacettepe Journal of Sport Sciences, 29(3), 131-146.

Yamak, B., Imamoğlu, O., Islamoğlu, İ., \& M., C. (2018). The effects of exercise on body posture. Turkish Studies Social Sciences, 13(18), 13771388.

Yayc1, L. (2013). Validity and reliability study of D2 attention test. Kalem Journal of Education and Human Sciences, 3(1), 43-80. 